\title{
¿Qué es un embrión? Panorama de algunas posiciones filosóficas
}

What is an embryo? Panorama of some philosophical positions.

Anne Fagot-Largeault

Profesora en la Universidad de París X (Filosofía)

Geneviève Delaisi de Parseval

Psicoanalista

José Luis Solana Ruiz (traducción y adaptación)

Departamento de Antropología, Geografía e Historia. Universidad de Jaén (España)

\begin{abstract}
RESUMEN
Los autores exponen las principales posiciones éticas asumidas en el debate sobre el estatuto del embrión y del feto humano (¿se les puede o debe atribuir el estatus de persona?, ¿tienen derechos?, ¿se les debe algún tipo de respeto?), debate que se ha planteado en relación a temas como el aborto, las técnicas de fecundación in vitro, y la investigación e intervención biomédicas. Distinguen tres posiciones éticas principales, de las que muestran las dificultades y contradicciones que entrañan: la posición vitalista, según la cual el ser humano es persona desde el momento de su concepción; la posición relacional, que basa el estatuto de persona, la dignidad y el respeto en la autonomía y la racionalidad; y la posición pragmática, que aparca la reflexión y discusión sobre el estatuto ontológico del feto y del embrión humano para centrarse en la búsqueda de acuerdos racionales sobre cómo tratar a estas entidades, atendiendo al sufrimiento que se les pueda o no causar. Concluyen apuntando una cuarta posición posible: una ética fundada en una ontología progresiva que atienda a las fases de desarrollo del ser embrionario y que, en consecuencia, centre la reflexión y las decisiones éticas sobre el estatuto de persona del embrión en los umbrales y las etapas del desarrollo embrionario.
\end{abstract}

\section{ABSTRACT}

The authors present the main ethical positions taken in the debate on the status of the embryo and the human foetus (Can the foetus or should it be granted the status of a person? Does a foetus have rights? Does the foetus deserve respect?). The debate has arisen in relation to issues such as abortion, in vitro fertilization techniques, and biomedical research and intervention. Three main ethical positions are distinguished, showing the difficulties and contradictions posed: vitalist position, according to which the human being is a person from the moment of conception; the relational position, which refers to a person-based status, dignity, and respect in autonomy and rationality; and pragmatic position, which leaves aside the reflection and discussion of the ontological status of the human embryo and foetus to focus on finding rational agreements on how to treat the embryo and the human foetus, considering the suffering that they may or may not cause. The authors conclude by pointing out a fourth possible position: ethics based on an ontology that refers to progressives stages of human embryonic development and therefore focuses on reflection and ethical decisions concerning the status of the embryo in individual thresholds and stages of embryonic development.

PALABRAS CLAVE

aborto |feto| estatuto de persona| bioética

KEYWORDS

abortion | foetus | status of the person | bioethics

\section{Introducción}

En el transcurso de la década de 1970 (que fue en varios países la década de la liberalización del aborto), la cuestión del estatuto del embrión humano fue debatida sobre todo en términos de libertades individuales: derecho de las mujeres a disponer de sí mismas versus derecho a la vida del feto en el interior de la madre. En la década de 1980, con la aplicación de técnicas de procreación artificial al tratamiento de la esterilidad humana, el acento se puso en la responsabilidad colectiva hacia el embrión separado, concebido en probeta, metido en el congelador, codiciado por la investigación cuando no se 
restituye al útero materno. Pero no existe consenso sobre los fundamentos filosóficos de la protección jurídica debida al embrión. El presente artículo no tiene como fin añadir una tesis más a una literatura internacional ya considerable sobre estos temas, sino situar posiciones y argumentos enfrentados, para esclarecer un debate que afecta, entre otros asuntos, a las fuentes del respeto debido a la persona humana.

A finales de la década de 1980 dicho debate fue estimulado en Francia por el tránsito inminente "de la ética al derecho" (Conseil d'État 1988). El ante-proyecto de ley "sobre las ciencias de la vida y los derechos del hombre" (1989) se inspiró en parte en la ley australiana, como lo reconoció su autor, Guy Braibant (Libération, 28 marzo 1989). Ese ante-proyecto planteó que, con respecto al embrión in utero, el embrión humano in vitro "presenta una vulnerabilidad particular que supone una protección jurídica acrecentada". Para otorgar esa protección se propuso asimilar el embrión "artificial" al embrión "natural", amparándolo bajo un "proyecto parenteral de procreación" conforme al "modelo clásico de la familia plena" (un padre, una madre, un niño deseado): la fecundación in vitro (FIV) podía realizarse si la demandaba una pareja que quisiese un niño (se excluyó hacer una FIV a una mujer célibe o crear embriones para la investigación); los embriones se conservarían hasta cinco años para permitir a la pareja realizar su proyecto; si durante el transcurso de esos cinco años la pareja renunciaba a su proyecto, podía exigir la destrucción de los embriones; si el proyecto se llevaba a cabo con éxito, la pareja podía donar sus embriones sobrantes a otra pareja o para la investigación; si la pareja se disolvía (por la muerte, el divorcio, la separación), era imposible cualquier utilización de sus embriones; con la expiración del plazo de cinco años los embriones que permaneciesen en el congelador serían destruidos.

La investigación sobre el embrión humano -juzgada indispensable desde el momento que la procreación medicamente asistida es admitida como paliativo de la esterilidad de las parejas- se autorizaba, pero quedaba estrictamente delimitada. Los investigadores solo podían recurrir a los embriones excedentes que los genitores aceptasen expresamente que fuesen utilizados para la investigación; en condiciones experimentales, quedaba prohibido dejar al embrión desarrollarse más de siete días (excepcionalmente, catorce); el protocolo de investigación debía ser aprobado por el Comité Nacional de Ética; se prohibían todas las investigaciones que pudiesen "perjudicar la integridad del género humano o conducir a prácticas eugenésicas".

Resulta paradójico que una ley organizase la destrucción de los embriones, en lugar de simplemente prohibir su reimplantación en el cuerpo de la mujer, pasado el plazo de cinco años. El proyecto de ley francés intentó conciliar la aceptación del tratamiento médico de la esterilidad en casos individuales con la preocupación por proteger a la sociedad contra las tentaciones de los investigadores y los fantasmas de las familias, sin tomar partido sobre el estatuto ontológico del embrión o del feto humano ("un ser sin poder de expresión", "un proceso de vida", "una persona humana potencial"). ¿Acaso no es indispensable resolver esta cuestión para encontrar un compromiso aceptable con respecto a la moral común?

\section{¿Cuándo comienzan los derechos del hombre?}

Bajo el pretexto de un objetivo terapéutico (tratamiento de la esterilidad) o preventivo (erradicación de taras hereditarias) las técnicas relacionadas con la concepción nos han habituado a que los gametos humanos 0 el embrión humano sean manipulados como objetos (congelados, almacenados, descongelados) y/o tratados como medios (utilización de tejidos fetales para tratar déficit inmunitarios o neurológicos). Igualmente, se ha planteado, a propósito de la extracción de órganos de "bebés donadores", la posibilidad de que algunos padres conciban y traigan al mundo a un niño con la finalidad de utilizar sus órganos para salvar una vida. Kant dijo que la ley moral puede formularse así: "Actúa de manera que trates a la humanidad, en tu persona como en la de los demás, siempre al mismo tiempo como un fin, nunca solamente como un medio" (Grundlegung zur Metaphysik der Sitten, 1785). Este principio de respeto a la persona humana es proclamado por la Declaración universal de los derechos del hombre y por las constituciones de la mayoría de los países. Es reconocido como un principio esencial, 
incluso si está lejos de ser siempre respetado (como ponen de manifiesto los informes de Amnistía Internacional). ¿Existe conflicto entre el principio del respeto debido al ser humano y la instrumentalización de este ser en los estadios embrionario o fetal (1) -a menos que un embrión humano no sea una persona humana?

Los "derechos del hombre" comienzan, jurídicamente, con el nacimiento. "Los hombres nacen y permanecen libres e iguales en derechos" (Declaración de los derechos del hombre y del ciudadano, 1789). "Todos los seres humanos nacen y continúan siendo libres e iguales en dignidad y derechos. Están dotados de razón y conciencia, y deben obrar unos para con otros con espíritu de fraternidad" (Declaración universal de los derechos del hombre, ONU, 1948).

¿Y antes del nacimiento? Aquí, las nociones jurídicas son imprecisas o poco coherentes. En Francia, a finales de la década de 1980, el derecho a la herencia (por consiguiente, la personalidad jurídica) regía desde el día de la concepción, de modo condicional (es decir, a condición de que el niño naciese vivo y fuese viable). La ley que garantizaba (paradójicamente, en apariencia) "el respeto a todo ser humano desde el comienzo de la vida" fue la que descriminalizó el aborto (ley del 17 de enero 1975, Ilamada ley Veil). Y mientras que los malos tratos a niños eran punibles con sanciones penales, no se podía llevar a una mujer embarazada ante un tribunal bajo pretexto de malos tratos al feto (si, por ejemplo, se alcoholizaba). Tampoco se podía imponer a una mujer embarazada que rehusase una intervención quirúrgica sobre el feto que portaba, incluso si esa intervención era decisiva para el porvenir del feto. Caricaturizando un poco esto: el feto, como futuro niño, tiene derecho al patrimonio sin tener derecho a la vida o a la salud (Théry 1982).

En los Estados Unidos se emprendieron acciones judiciales en nombre de niños con discapacidades que reprochaban a sus padres (o a los médicos) haberlos dejado nacer (wrongful life suits), como si fuese más grave ayudar a vivir a un feto deficiente que recurrir al aborto (para un niño con discapacidad es justo lo inverso: se considera que es más grave matarlo que mantener su existencia de incapacitado). Pero ese derecho a la salud y a la integridad física, hasta cierto punto admitido por la jurisprudencia americana, solo de manera condicional es un derecho del feto: para el niño viviente se acuerdan eventuales compensaciones por el prejuicio de que las causas son anteriores al reconocimiento de su existencia como persona.

Por lo que a la vida fetal se refiere, puede ser protegida por la ley sin que esto implique un derecho (véase Bondeson y otros 1983: 107-117 y 119-157). Por otra parte, la vida fetal está protegida de manera desigual según los países; el plazo legal para la interrupción voluntaria del embarazo varía de un país a otro y ha cambiado a lo largo del tiempo. La Corte Suprema de los Estados Unidos confirmó en 1973, a propósito del caso Roe vs Wade, que el feto no era una "persona" que tuviese derechos constitucionales. Desde el punto de vista de la common law británica, el aborto nunca ha sido un homicidio (pues no hay persona humana alguna que sea eliminada); el aborto tardío era un crimen, y como tal punible; el aborto precoz era ignorado. ¿Esta distinción implica que la ley deba ignorar a los jóvenes embriones manipulados en el laboratorio? En algunos países (Australia, Gran Bretaña, Estados Unidos), las asociaciones que militan a favor del "derecho a la vida" han intentado imponer que la dignidad de la persona sea constitucionalmente garantizada a todo ser humano desde su concepción. Sin embargo, la célula (cigoto) resultante de la fecundación de un ovocito por un espermatozoide no parece poseer los rasgos mínimos que permitirían conferirle el estatuto de persona. ¿Cuáles son esos rasgos? El derecho no lo dice.

Que los criterios jurídicos no estén claros incita a una reflexión filosófica. ¿Qué es lo que constituye la dignidad humana y funda el respeto del hombre por el hombre? "El respeto se aplica siempre únicamente a las personas, nunca a las cosas", escribe Kant (Kritik der Praktischen Vernunft, 1788). El ser humano es respetable en tanto que persona. Una tradición filosófica bastante coherente vincula esta noción de persona a la de ser con razón (2)."Los seres racionales son llamados personas" (Kant 1785).

Pero existe incertidumbre respecto al fundamento ontológico de la personalidad. Dos posiciones extremas se enfrentan. Según unos, para ser persona basta con poseer el genoma humano, con 
pertenecer a la especie humana: el criterio pertinente es biológico o natural. Según otros, es necesario para ser persona- poseer suficiente conciencia y razón para formar parte de la comunidad de sujetos libres y ejercer la autonomía moral: el criterio pertinente es ético o cultural. Tras examinar estas dos tesis, escucharemos a aquellos que, juzgándolas inconciliables, proponen abandonar el terreno de la ontología y buscan las bases de un acuerdo práctico: la cuestión no sería tanto saber si el embrión es o no es una persona, sino definir reglas de buena conducta al respecto. Pero ocurre que las deontologías esbozadas hasta aquí implican una ontología "intermediaria", que se busca a través de la reordenación de las fronteras precitadas o del abandono del dualismo cosas/personas.

\section{La corriente vitalista}

Continuemos, primero, con los partidarios de un criterio biológico de la presencia, o de la ausencia, de una persona humana. La persona es coextensiva al organismo que la sostiene y expresa. Dura tanto como este organismo vive. En consecuencia, desde su concepción, y hasta su último estertor, el ser humano es enteramente una persona. El embrión de algunos días, el anciano senil, el enfermo en estado de coma crónica tienen la misma dignidad que usted y que yo, y tienen derecho al mismo respeto.

Esta posición, enseñada en muchas tradiciones religiosas o místicas (se ha dicho que era una doctrina secreta de los pitagóricos; véase Bondeson y otros 1983: 296-298), es compartida espontáneamente por muchas personas en la vieja Europa impregnada de cristianismo. Ha sido reafirmada últimamente con solemnidad en el seno de la Iglesia católica. "Desde el momento de su concepción, la vida de todo ser humano debe ser absolutamente respetada" (Congregación para la Doctrina de la Fe 1987: Intr., § 5), y también: "El fruto de la generación humana desde el primer instante de su existencia, es decir, a partir de la constitución del cigoto, exige el respeto incondicional moralmente debido al ser humano en su totalidad corporal y espiritual. El ser humano debe ser respetado y tratado como una persona desde su concepción y, por consiguiente, desde ese momento se le deben reconocer los derechos de la persona..." (Congregación para la Doctrina de la Fe 1987: I, 1). El yo ontológico, explica A. Moraczewski (en Bondeson y otros 1983: 301-311), no debe confundirse con el yo psicológico (que solo es coextensivo a la vida consciente), ni con el yo legal (que solo existe en los límites arbitrarios de una inscripción en el estado civil). La capacidad de un desarrollo plenamente humano es dada desde la primera célula embrionaria, es inherente al genoma. Sería absurdo pretender que este yo ontológico comience tras nueve meses de desarrollo o se interrumpa si el ser se ve momentáneamente aquejado de incapacidad. "Desde que el óvulo es fecundado se encuentra inaugurada una vida (...), desde el primer instante se encuentra fijado el programa de lo que será ese viviente" (Congregación para la Doctrina de la Fe 1987: I, 1). Se le ha reprochado a los integristas de la tesis "biológica" confundir "vida humana" y "persona humana" (véase Bondeson y otros 1983: 131-132), pero el reproche es injusto, porque esa confusión es la tesis misma.

Una dificultad (real) de esta tesis es que distingue mal el respeto del hombre hacía el hombre de un egoísmo de la especie: ¿por qué un "vegetal" humano es radicalmente más respetable que un animal viviente, capaz de sentir y de sufrir?, y ¿por qué el respeto no se le debe también a los animales? La Iglesia católica responde: "El hombre es sobre la Tierra la única criatura que Dios ha querido por sí misma" (Congregación para la Doctrina de la Fe 1987: Intr., § 5). Otras tradiciones espirituales juzgan ingenuo este antropocentrismo y extienden el respeto a la vida al menos a una parte del mundo animal. La intuición es análoga: lo que está vivo (humano o animal) es respetable porque vive. La vida es un valor (Congregación para la Doctrina de la Fe 1987: § 4). El bien consiste en vivir en armonía con la naturaleza (a lo que Schopenhauer ya redarguyó que la naturaleza no respeta lo viviente: lo despilfarra).

Puede sorprender ver a algunas personas religiosas, por otra parte convencidas del destino espiritual del hombre, aferrarse a un criterio biológico -incluso genético- de la persona. La objeción ha sido prevista. La ontología substancialista que acaba de ser evocada (el hombre es un viviente racional) se completa, en las religiones reveladas, con una ontología relacional (ese "ser racional" es suscitado en el hombre biológico por la llamada de otra Persona). "Yahvé me ha llamado desde el vientre de mi madre..." 
(Isaías, 49, 1). Es la alianza del Creador con su criatura la que "personaliza" al individuo humano y lo eleva más allá de su condición animal. La humanidad en el hombre es un don de Dios, la "persona" humana resulta de una elección divina (véase por ejemplo, Thévenot 1985).

¿Cuándo y cómo se realiza esa elección? Esta no es una pregunta que resuelvan los biólogos. "La biología nada puede decir sobre la 'personalización' del embrión humano", afirma un teólogo (Tettamanzi 1986). Esa pregunta concierne a los teólogos, los filósofos, los juristas. Pero, al mostrar que el desarrollo se hace sobre la base de un patrimonio genético individual definitivamente fijado desde el momento de la fecundación del óvulo por el espermatozoide, el biólogo ofrece al filósofo una garantía objetiva "para extender el concepto ontológico de sujeto personal (... ) al nivel embrionario" (Tettamanzi 1986) y permite así justificar la elección hecha por los teólogos "ortodoxos" de la doctrina de la animación inmediata.

Cabían muchas formas de concebir el modo como Dios insufla ese alma espiritual en el ser humano. Podía (tesis 1) haberla insuflado una vez para todos en nuestros primeros padres (tesis de Tertuliano), que la hubiesen trasmitido (al mismo tiempo que el pecado original) a su descendencia. Esta hipótesis, que a los ojos de San Agustín tenía la ventaja de explicar la transmisión del pecado, implicaba la presencia del alma en la simiente humana, lo que daba a la procreación humana una participación considerable en la potestad del poder divino. El alma podía, también, ser objeto de una creación especial en cada generación. En esta eventualidad: o bien (tesis 2) Dios la crea al mismo tiempo que, mediante el acto generador, los padres conciben un nuevo ser (animación inmediata: tesis de Gregorio de Niza); o bien (tesis 3) Dios termina la obra de carne en el momento en que el feto está lo suficientemente desarrollado para comenzar a ejercer una actividad espiritual (animación mediata: Tomás de Aquino, "el alma intelectiva es creada por Dios al término de la generación humana", Summa Theologiae, 60, I Quest. 118, Art. 1). Para Tomás de Aquino, el gesto de Dios que infunde el alma es reclamado por el organismo en un determinado estadio de su desarrollo. ¿Qué estadio? Después de que todas las funciones vegetativas, y luego las sensitivas y motrices, hayan sido puestas en funcionamiento, lo que correspondería aproximadamente al momento en que la madre comienza a sentir moverse el feto. Tomás de Aquino se apartó en esto de la opinión de Aristóteles (quien pensaba que ese momento es menos precoz para las niñas que para los niños: véase Hist. Anim. VII, 3, 583 b 24). Tomás de Aquino admite, en consecuencia, que el aborto no es un homicidio antes de la animación (Summa Theologiae, II, 2, Quest. 64, Art. 8). Esta doctrina figura en el derecho canónico de la Iglesia católica de 1234 a 1869.

Los filósofos y teólogos han buscado frecuentemente en la biología indicios de la plausibilidad de una u otra hipótesis. La posición tomista es compatible con la concepción epigenetista del desarrollo embrionario, que era la de Aristóteles. Leibniz intentó conciliarse con la teoría preformacionista de su época: "Creería que las almas, que serán un día almas humanas como las de otras especies, han estado en las simientes y en los antepasados hasta Adán, y han existido en consecuencia desde el comienzo de las cosas, siempre en un modo de cuerpo organizado: parece que M. Swammerdam, el R. P. Malebranche, M. Bayle, M. Pitcarne, M. Hartsoeker y muchas otras personas muy hábiles son de ese parecer. $\mathrm{Y}$ esta doctrina se encuentra bastante confirmada por las observaciones microscópicas de $\mathrm{M}$. Leuwenhoeck y de otros buenos observadores. Pero también me parece conveniente por varias razones que las almas solo puedan existir como almas sensitivas o animales, dotadas de percepción y sentimiento, y carentes de razón; y que permanecen en ese estado hasta el tiempo de la generación del hombre al que han de pertenecer, pero solo entonces reciben la razón; sea que haya un medio natural de elevar un alma sensitiva al grado de alma racional (lo que me cuesta trabajo concebir), sea que Dios haya dado la razón a esa alma mediante una operación particular o, si se quiere, por una especie de transcreación" (Leibniz, Discurso de metafísica, 1710, § 91). Leibniz es, pues, partidario de la animación inmediata (tesis 2), si bien confiesa que preferiría ser enteramente preformacionista (tesis 1) si hubiese sabido resolver el problema planteado por el derroche natural de la simiente: ¿los gérmenes que deban dar lugar a una persona humana pueden ser preseleccionados por Dios y ser los únicos portadores del alma racional, mientras que los otros, idénticos, que no dan lugar a nada, serían puramente animales? (Discurso de metafísica, § 397).

El problema no es académico. Según los datos científicos actuales, una mujer emite durante el curso de su vida genital aproximadamente 300 óvulos fecundables, un hombre produce cien millones de 
espermatozoides por mililitro de esperma, mientras que el número de niños realmente traídos al mundo ronda los dos por pareja (en los países desarrollados) y rara vez sobrepasa los doce. Así, pues, el número de "personas posibles" excede considerablemente al de "personas reales", y es difícil pensar que los gametos que no encuentran nunca su "pareja" sean en esencial diferentes de aquellos que terminan en una fecundación. De aquí la ventaja de la tesis 1. Leibniz quizás hubiese suscrito, por las mismas razones, la tesis 3 si hubiese sabido lo que hoy sabemos del despilfarro natural de la vida embrionaria: dos de tres óvulos fecundados mueren durante las seis primeras semanas (la detención del desarrollo sería debida a una aberración cromosómica casi en la mitad de los casos). Es menos fácil creer que Dios se divierte con este despilfarro antes de haber suscitado la persona (tesis 2) que pensar que espera que el grueso de la selección sea hecha para acordar la animación (tesis 3). El envite es grave para un cristiano que crea en la redención por el bautismo. En la Edad Media se discutía si era necesario bautizar los productos de los malos partos. Un partidario de la tesis 2, que creyese como San Agustín que toda persona humana muerta sin bautismo está condenada, debería lógicamente abstenerse de toda vida sexual (Ensayo de Teodicea, 1710, § 92 a 95).

Creer en la animación inmediata es, pues, creer que el acto creador por el cual Dios infunde en el nuevo ser humano su alma espiritual tiene lugar en el momento de la concepción de ese ser (esa concepción que hoy puede realizarse en probeta). Al adoptar esta doctrina se pretende excluir a la vez la posibilidad de que los gametos (óvulo y espermatozoide), mediante los que los padres trasmiten la vida, sean seres personales (tesis 1) y la eventualidad de que el embrión pase por una fase prepersonal de desarrollo antes de acceder a la plena realización de su humanidad (tesis 3). Es necesario apuntar que oficialmente la Iglesia católica guarda prudencia en relación a estas doctrinas. "El Magisterio no se ha comprometido de modo expreso con una afirmación de naturaleza filosófica", dice la instrucción de la Congregación para la Doctrina de la Fe (1987: I, 1), que afirma, sin embargo, que "el alma espiritual de todo hombre es inmediatamente creada por Dios" (Congregación para la Doctrina de la Fe 1987: Intr., § 5). La declaración sobre el aborto de la misma Congregación (de 1974) decía que, incluso si hay duda sobre el hecho de que el embrión precoz sea una persona humana, se debe actuar como si lo fuese y respetar su vida, pues constituiría una grave falta asumir el riesgo de un homicidio.

Esta noción de riesgo está muy presente en los argumentos utilizados para defender las implicaciones de la posición "biológica" estricta, a veces llamada también "vitalista" (véase Comisión de Reforma del Derecho de Canadá: 1979: cap. 2). Uno de los más corrientes (y de los más mediocres) es el argumento de la "pendiente resbaladiza", según el cual no se debe comenzar a conceder que el embrión precoz no es una persona de manera plena, porque, si se comienza, no se sabrá parar. Este argumento puede tomar perfectamente varias formas, por ejemplo: es necesario prohibir a los investigadores observar el desarrollo in vitro del óvulo fecundado, porque, si se les permite observarlo, no podrán contenerse para no manipularlo y toda manipulación experimental constituye una amenaza para la integridad del óvulo. El fundamento último de la demostración es la siguiente premisa: "Estamos abocados de manera irresistible a realizar todo lo que es técnicamente realizable", o también: "No sabemos imponernos límites". Pero la moral consiste justamente en poner límites y es poco coherente pedir una prohibición cuando se presupone que las prohibiciones siempre se transgreden.

Otro argumento, que resulta en parte del primero, establece que no es necesario "rebasar los límites de una razonable dominación de la naturaleza" (Congregación para la Doctrina de la Fe 1987: Intr., § 1). Los avances científicos y técnicos que establecen nuestro "señorío" (Congregación para la Doctrina de la Fe 1987: I, 2) sobre la naturaleza deben detenerse en el umbral de la vida personal. Son conocidas las reservas de la Iglesia católica respecto a las técnicas que permiten el dominio sobre la procreación humana, aun cuando nunca ha objetado contra una racionalización de la procreación animal. La Iglesia católica denuncia el control de la fertilidad humana, incluso cuando ese control está enteramente orientado hacia el don de la vida, como "una dinámica de violencia y dominación" (Congregación para la Doctrina de la Fe 1987: II, 29). La misma inquietud fue expresada en Francia por el Comité Nacional de Ética de este país: es necesario "evitar que una relación de omnipotencia se instituya sobre lo humano en nombre del progreso científico" (1986: § 7). Y esa omnipotencia no es solamente el poder de dar la vida y la muerte a un ser sin defensa que es visado, es el poder de conocerlo en su intimidad, de prever lo que será, como si el conocimiento científico del hombre fuese por sí mismo una violación de la 
personalidad. El dogma de la imposibilidad a priori de las ciencias humanas (difundido entre los medios filosóficos) procede del mismo temor.

Esto nos conduce a un tercer argumento que se apoya en el principio del "carácter sagrado de la vida". Este principio es considerado como si implicase un derecho del ser vivo a la vida y, por consiguiente, un deber de hacerle vivir. Este argumento va con frecuencia ligado a la creencia de que también una ciencia de la vida es ilegítima, porque no se puede hacer un estudio experimental sobre un ser vivo sin matarlo (esto es falso, pero algunos autores destacados lo han creído, como el físico Niels Bohr, que contribuyó a propagar esta idea en la década de 1930).

La aplicación del principio del carácter sagrado de la vida al periodo prenatal de la vida humana es delicado. Si se considera que, en las condiciones naturales de la procreación, dos de cada tres óvulos fecundados mueren durante las seis primeras semanas (véase Biggers en Bondeson y otros 1983: 46) y si se le reconoce a esos óvulos un derecho a la vida, ¿no deberíamos correr a socorrerlos e intentar por ello hacerlos sobrevivir más tiempo, como nos hemos esforzado desde el último siglo en reducir la mortalidad de los niños de poca edad (con el resultado que se conoce)? Esto conduciría a desarrollar a lo mejor la investigación sobre la desarrollo embrionario precoz y las técnicas de asistencia a la procreación, de lo que se deriva una ingerencia en el secreto del óvulo y del cuerpo femenino, insoportable en relación con el argumento precedente. El "derecho a la vida", pues, será entendido solo como un derecho a una "oportunidad de vida" y el deber como deber de "dar una oportunidad", de no matar deliberadamente, de no interferir en la selección natural. "El hombre no debe sustituir a Dios".

Y he aquí un cuarto tipo de argumento: solo Dios es dueño de la vida. Se cree que se trata de una tautología, porque vemos que el poder humano de "crear" vida se reduce (en la cama como en el laboratorio) a crear la ocasión de un encuentro entre dos células... vivientes. Lo que no constituye un poder verdaderamente creador. Pero se trata de otra cosa. Leibniz decía que Dios, entre todas las "personas posibles" de las que tiene idea (de las que concibe la esencia), "escoge para la existencia" aquellas que quiere, por razones que resultan de la armonía global del universo (Discurso de metafísica, 1686, § 31). Estas razones divinas nos trascienden, como seres limitados que somos. Nuestra idea de lo mejor es parcial, sobre todo negativa: no queremos traer al mundo un niño trisómico, preferimos un sexo a otro; en suma, si pudiésemos saber lo que resultará de la unión de dos gametos, serían los resultados lo que recusaríamos (3). Ahora bien, gracias al diagnóstico prenatal in vivo y al diagnóstico genético in vitro accedemos a conocimientos que permiten rectificar las elecciones divinas, hasta escoger nosotros mismos, según nuestros propios criterios, quién merece existir. Temible poder. Es necesaria una sabiduría superior a la nuestra para otorgar un derecho a la existencia.

La versión laica del mismo argumento reemplaza a Dios por el azar: se debe respetar "la lotería genética" (CCNE 1986: § 18). Una versión alternativa (Ibid.) dice que la responsabilidad de impedir ser a una persona potencial solo debería corresponder al hombre en condiciones muy difíciles, que harían la decisión dolorosa. Sin embargo, es dudoso que el dolor haga sabio. Los defensores de la posición vitalista estricta han argüido siempre que, al propagar la vida, el hombre es la ocasión, si no el autor, de un don de existencia que implica una elección (selección natural) sobre lo que va a venir al ser entre una multitud de posibles y que resulta una locura humana pretender encargarse de esa elección. Todos estos argumentos son, subrayémoslo, de inspiración consecuencialista. "Hay peligro efectivo para el futuro del mundo, a menos que no sobrevivan hombres más sabios" (Congregación para la Doctrina de la Fe 1987: Intr., § 2).

Las implicaciones éticas de la posición "biológica" son bien conocidas. Toda vida humana merece el mismo respeto, toda vida concebida en el seno de la especie humana es vida de una persona. En consecuencia:

1) La interrupción voluntaria del embarazo no es más admisible que el infanticidio o que el homicidio de un hombre adulto. No se debe matar, ya se trate de contracepción (4), de aborto "por conveniencia" (IVG) o de aborto "terapéutico" (por malformación fetal). Cuando la vida del feto pone en peligro la de la madre, se puede en rigor invocar la "legítima defensa". Pero el feto no tiene 
intención de hacer daño. El derecho a la vida de un ser humano inocente es "inviolable" (Congregación para la Doctrina de la Fe 1987: Intr., § 4).

2) Las intervenciones médicas (de diagnóstico o terapéuticas) sobre el feto solo son legítimas si se hacen sobre seguro para su bien y sin peligro real para su vida. Se prohíbe utilizar un embrión o feto viviente con fines de investigación científica, incluso bajo un pretexto humanitario (la comisión nacional americana estableció un "principio de igual trato" para todos los fetos, contra quienes pensaban que los fetos destinados de todas maneras al aborto podían utilizarse legítimamente como objetos de experimentos, en especial sobre los efectos de medicamentos (véase el análisis de Leroy Walters en Bondeson 1983: 17-22).

3) En caso de muerte del feto, se le deben a sus restos las mismas atenciones que a los restos de otros seres humanos.

4) En la hipótesis de que la fecundación in vitro sea tolerada (para tratar la esterilidad), es necesario evitar el desperdicio de embriones "supernumerarios" y todas las manipulaciones (como la congelación) que conlleven pérdida de posibilidades. El embrión obtenido in vitro debe ser reimplantado en los mejores plazos.

De hecho, la posición estricta (véase Tettamanzi 1986) considera que ningún procedimiento "artificial" de procreación es aceptable, porque la puesta a punto de los actos técnicos necesita ensayos previos, pruebas, fracasos..., por consiguiente, un desperdicio de vida ocasionado por la voluntad humana. Los preceptos enumerados se resumen en uno solo: debemos servir a los propios fines del embrión, no utilizarlo como medio para otros fines que los suyos. El fin presumible del ser en gestación es vivir y desarrollarse. Pero, protestan los que no comparten el punto de vista vitalista (por ejemplo, Singer y Kuhse), es absurdo aplicar el imperativo kantiano a un ser desprovisto de fines racionales (universalizables). Entre los creyentes, esta objeción se elude mediante el argumento de que los fines orgánicos internos al embrión entran en los designios de Dios, que es ciertamente una persona. Lesionar al embrión es, entonces, faltar al respeto debido a Dios (o, de todos modos, a una racionalidad natural que trasciende al individuo).

Si se sigue la posición "biológica" hasta el plano legislativo, todo (o casi todo) lo que hoy se investiga en el dominio de la procreación debería estar prohibido. Así, el proyecto de ley propuesto (no adoptado) en Australia por el senador Harradine (Human Experimentation Act, 1985) prohibía los tentativas experimentales sobre el embrión humano, salvo aquellas que pudiesen contribuir a su bienestar. La Iglesia católica juzga lícitos los ensayos para corregir taras genéticas en el estado embrionario, a condición de que esos ensayos sean compatibles con la supervivencia del embrión. Juzga ilícita toda investigación sobre el embrión humano, distinta de esas tentativas empíricas. La investigación debe hacerse sobre el animal. La legislación que adoptó el estado australiano de Victoria fue menos severa. Este estado fue el primero del mundo en dotarse de medios jurídicos para controlar los nuevos métodos de procreación (Infertility Medical Procedures Act, 1984). Prohibió, no la investigación sobre el embrión, pero sí la creación de embriones humanos con un fin exclusivo de investigación. El promotor de la ley recurrió a un criterio de intencionalidad que, aunque laxo, tenía reminiscencias de la ética aquí caracterizada. Se estableció el derecho a utilizar para la investigación (con el consentimiento de los genitores) embriones creados con la intención de conducir a una procreación (en el marco del proyecto parenteral de una pareja estéril) y guardados en el congelador después que la pareja tuviese los niños que deseaba (embriones supernumerarios, spare embryos). No se estableció el derecho a fabricar un embrión expresamente para la investigación. "This individual and genetically unique human entity may not be formed solely and from the outset to be used as a means for any other human purpose, however landible". La distinción fue retomada por la comisión Benda en la RFA (Fécondation in vitro 1985: § 2412) y por el Comité Nacional de Ética en Francia (1986).

Kuhse y Singer (1986) objetan que la intención bajo la cual esa distinción está elaborada no constituye para el embrión diferencia alguna y que la ley de Victoria conduce a aberraciones: permite, por ejemplo, congelar un óvulo, descongelarlo, fecundarlo, transferir el embrión así obtenido a un útero, pero prohíbe 
asegurarse, antes de transferirlo, de que la congelación no acarree malformaciones embrionarias (porque sería necesario para ello fecundar óvulos sin intención procreadora). "Se prefiere, pues, arriesgar el nacimiento de niños anormales antes que permitir la creación y disección de embriones con el consentimiento de los progenitores"; estos autores ven en esto una "distorsión perversa de la ética" (Kuhse y Singer 1986).

Los defensores de la posición estricta ven más bien en ello la prueba de que una ley permisiva abre la puerta a los abusos (pendiente resbaladiza) y que es necesario prohibir todas las manipulaciones de embriones humanos en el laboratorio, cualquiera que sea su finalidad. La Iglesia católica llega hasta a hablar de un derecho del ser humano a ser concebido mediante el método natural (relación sexual) y dentro del matrimonio (5). La prudencia de los juristas, incluso cuando tienen simpatías por esta posición, se comprende con facilidad. Se puede, ciertamente, obligar a los médicos que practican la FIV a inscribir en registros a todos los embriones formados y a señalar su destino (como lo hizo una ley del Estado de Pensilvania, en USA). Pueden preverse sanciones para los investigadores que se dediquen a determinados tipos de investigaciones (como lo hizo la ley de Victoria) o uno puede negarse financiar con fondos públicos ensayos que no sean terapéuticos (como se hizo en los Estado Unidos). Pero difícilmente se puede restringir la libertad de las mujeres embarazadas tanto como se desea limitar la de los investigadores, o garantizar a los embriones "artificiales" más derechos que a los embriones "naturales". Sin embargo, los defensores del criterio biológico de la personalidad han luchado mucho para lograr que la ley prohíba todo lo que ellos condenan moralmente como atentado contra los derechos del hombre.

Si la radicalidad de esta condena dispensa de plantear problemas sobre fronteras (aquí, por ejemplo, se juzga ridículo discutir si la investigación sobre el embrión es permisible hasta los 14 días del desarrollo, los 17 o los 25), sin embargo, conduce a serios casos de conciencia. El embrión trisómico tiene el mismo derecho a vivir que el embrión normal: si el diagnóstico de la trisomía resulta posible en el estado embrionario precoz, ¿habrá que implantar a sabiendas el embrión trisómico e imponer esta prueba a los padres? ¿Hay que rechazar la hipótesis de que el diagnóstico prenatal de una malformación o de una enfermedad hereditaria conduzca a la decisión de abortar? ¿Hay que condenar los esfuerzos hechos para erradicar taras genéticas (como la talasemia) en las poblaciones afectadas?

En principio, se establece que no existe aquí problema de cualidad de la vida, que la miserable existencia de un niño talasémico tiene tanto valor como la de un niño "normal". En la práctica, se tiene en cuenta con frecuencia el sufrimiento infligido, nos sentimos forzados a escoger un mal para evitar otro mal: se destruye el feto talasémico para evitarle una vida dolorosa al niño que nacerá, así como a su familia. Sentiremos culpabilidad por ello, como la sentiríamos si lo dejásemos vivir. En el límite, puede haber en ello una especie de suicidio moral, por negarse a escoger. No se quiere asumir la responsabilidad de hacer morir a un prematuro incapacitado, "se deja elegir a la naturaleza", esperando que esta le hará morir (6). Detrás de la rigidez de los principios planteados hay, pues, una visión trágica de la vida moral: cuando el hombre sustituye con sus decisiones las de la naturaleza, no puede más que hacer el mal.

\section{La corriente relacional}

En una oposición opuesta a la anterior se encuentran los neo-kantianos, para quienes lo que constituye la dignidad humana es la autonomía de la voluntad. Recusan el criterio biológico, haciendo valer que para ser una persona no es necesario ni suficiente poseer el genoma humano (Engelhardt 1986: cap. 4). Otorgamos un estatuto de persona a colectividades (los Estados son personas morales), no otorgamos el estatuto de persona a nuestras células somáticas (todas las cuales tienen el potencial de dar lugar, mediante clonación, a un individuo humano). El respeto por la personalidad, en el hombre, es "un respeto por algo que es completamente distinto a la vida", decía Kant (1788). Una persona en el sentido propio es decir, en el sentido ético- del término es un ser racional que se obliga a inclinarse solo ante la ley que él mismo erige como universalizable. Es un sujeto libre, a quien el Bien no es dictado: él lo juzga por sí mismo, decide por sí mismo y reconoce a sus semejantes la misma prerrogativa. 
Así, el ser humano que asume sus responsabilidades de hombre entra con los otros seres racionales en un reino moral que no es el reino natural: trasciende la naturaleza, le prescribe fines. "Un mundo de seres racionales (mundus intelligibilis) es posible por la capacidad para legislar que tienen todas las personas que son miembros de dicho mundo" (Kant 1785). En este mundo inteligible no se trata de "hacer el bien a los otros por amor a ellos" (Kant 1788), sino de respetar en ellos la dignidad del legislador, es decir, de no imponerles nada que no quieran. Engelhardt (1986: cap. 4) llama "comunidad moral pacífica" a lo que Kant llamaba "reino de los fines". La condición de posibilidad de una "comunidad moral pacífica" es precisamente que cada uno trate al otro "también como un fin" y que las disensiones eventuales sobre lo que debe ser hecho (en materia legislativa o reglamentaria, por ejemplo) se resuelvan mediante la negociación entre interlocutores que se consideran mutuamente como fuente (y no solamente como objeto) de la moralidad.

El ejercicio de la autonomía moral no necesita grandes talentos ni eminentes virtudes. Kant lo había dicho (1785): la "facultad de juzgar en cuestiones prácticas" se encuentra entre las gentes más simples. Pero no se "nace" autónomo. "El hombre solo llega a ser hombre mediante la educación" (Kant). Muchos seres humanos permanecen "menores" durante toda su vida (Kant 1784) y solo participan en la comunidad moral bajo la autoridad de un "tutor", el cual les asiste en la práctica de sus derechos y deberes, y responde de ellos ante otras personas. Un "menor" no es enteramente una persona. Se ha discutido mucho sobre las condiciones de posibilidad de una autonomía personal mínima: conciencia de la identidad, capacidad para "proyectarse", aptitud para comunicar, etc. (véase Bondeson y otros 1983). Una lista de criterios fue propuesta por J. Flectcher (1972). Engelhardt (1986) observa solamente que hay un aprendizaje de la autonomía y que ninguna autonomía se establece sin algún sentido de lo justo y lo injusto (por consiguiente, sin un mínimo de conciencia y de razón). Se llega a ser una "persona" humana de manera progresiva, en el curso de la infancia, a medida que se accede a la responsabilidad ("edad de razón"); se cesa de ser una "persona" a veces mucho antes de morir de muerte biológica, cuando se zozobra en el deterioro senil o en un coma irreversible. En suma, los sostenedores de un criterio ético o cultural reconocen la persona en la existencia de una capacidad racional efectiva (identificada a veces, paradójicamente, con la presencia de un neocórtex funcional).

Esta ontología substancialista se completa, como en la posición precedente, con una ontología relacional (7): los miembros de la comunidad moral se respetan entre sí, es decir, apelan mutuamente a conducirse como seres autónomos (en la medida en que somos racionales y sensibles, libres y determinados, el respeto en el sentido kantiano tiene siempre a la vez el sentido de un reconocimiento del "hecho de la razón" y de una llamada a ser racional).

No se podría apelar a su autonomía a un ser que no tiene esa capacidad (en inglés: competence). En particular, esto no tiene el sentido de decir que es necesario tratar al embrión humano como una persona. Esa es la posición que, con ánimo de oposición, desarrolló H. T. Engelhardt (1986: cap. 4). Del mismo modo, un niño recién nacido no es aún una persona: los lazos humanos que teje le permitirán poco a poco construir su autonomía, a condición de que sea capaz de ese aprendizaje. Un recién nacido anencéfalo jamás será una persona. A fortiori un embrión humano, un feto, no son personas, justamente son personas futuras, o posibles, o probables. El valor de un embrión no reside en el hecho de una hipotética dignidad intrínseca, sino en su valor para las personas que esperan su "venida al mundo". El embrión humano por sí no posee más "derechos" que un animal: no se le debe respeto por su autonomía moral (no la posee); se le debe solamente, como a los animales, en consideración a su sensibilidad (no se le debe hacer sufrir). Por el contrario, a las personas actuales se les debe respeto por su autonomía: debemos no presionar a una mujer embarazada para que aborte, si no quiere abortar, ni para que conserve el niño si quiere abortar. El "principio de beneficiencia" es un principio ético distinto del "principio del respeto a las personas" y está subordinado a este. Constituye una falta moral más grave forzar a los padres a mantener a un recién nacido muy deficiente, si prefieren no dejarlo vivir, que abandonar ese recién nacido a su suerte.

Nótese que el aspecto relacional de la ontología de la persona permite conferir "derechos" a seres que no tienen plena capacidad de ejercer las responsabilidades de una persona (por ejemplo, los niños); pero esta extensión de la comunidad moral no puede trascender lo que autoriza el aspecto sustancial de esa 
ontología. A los seres que se encuentran más acá de la autonomía "mínima", la comunidad de personas puede decidir protegerlos (como se protege a la naturaleza), no respetarlos (como se respeta la autonomía de las personas).

Se espera, pues, que la ética sea aquí menos argumentativa que procedimental (Engelhardt 1986: cap. 2). No tengo que demostrar a otro agente moral que no tiene razón por querer una inseminación artificial, sino comprender su punto de vista e informarle del mío. Cuando las acciones colectivas son necesarias, los agentes morales deben forjar procedimientos de negociación que les permitan ponerse de acuerdo, por ejemplo, sobre el grado de protección que quieren dar a los embriones humanos (seguimiento médico gratuito del embarazo, reglamentos internos de los bancos de embriones, etc.). Esos acuerdos son contractuales y revisables, solo comprometen a quienes los subscriben, cada persona mantiene la libertad de no hacer lo que objete en conciencia ("cláusula de conciencia"). Los poderes públicos tienen por tarea defender la libertad de las personas, en especial la de las más vulnerables (jóvenes, enfermos, incapacitados, minorías étnicas) contra la coerción y la violencia. La contribución particular de los filósofos consiste en establecer, mediante un trabajo de reflexión crítica, la clara distinción entre lo que es "constitutivo" de la ética y lo que es solamente "exhortatorio" y que, por consiguiente, está sometido a discusión. No tenemos argumentos racionales decisivos para condenar moralmente a la mujer que interrumpe un embarazo normal, ni a la que rehúsa interrumpir un embarazo patológico, ni al investigador que quiere liberar a las mujeres de la carga del embarazo estudiando las condiciones del desarrollo del embrión fuera del útero materno (ectogénesis), ni al investigador que rehúsa participar en ese estudio. Las concepciones particulares del Bien son diversas y, en ausencia de negociación exitosa que nos ponga a todos de acuerdo sobre un punto, debemos habituarnos a tolerar que los otros hagan lo que nosotros desaprobamos: "One must often tolerate on moral grounds that which one must condemn on moral grounds" (Engelhardt 1986: 14). Pero no podemos tolerar la intolerancia, porque la autonomía de los agentes morales es la condición de posibilidad de la "comunidad moral pacífica", es decir, de la ética.

La única regla moral universal es, pues, la del respeto a las personas. Cada uno juzga lo que debe ser como lo entiende, a condición de reconocer en los otros la misma libertad. Respecto a los seres desprovistos de autonomía personal, solo hay, como se ha dicho, deberes de beneficencia. En consecuencia:

1) La vida no debe ser despilfarrada sin necesidad ni de manera inútilmente cruel: esta regla se aplica a los seres humanos prepersonales tanto como a los animales. Por consiguiente, es deseable que la creación de embriones humanos in vitro y su destrucción no se hagan de manera anárquica, o que los métodos de aborto tardío tengan en cuenta el desarrollo neurológico del feto y le eviten sufrir. Pero, en la medida en que el ser biológicamente humano que se suprime no es una "persona", no se podría aquí decirle a la mujer portadora de un dispositivo anticonceptivo, al investigador que deja "volatizarse" al embrión congelado con el consentimiento de los progenitores (Jouannet 1986), a los padres que deciden no dejar sobrevivir a su recién nacido lisiado, que cometen un "crimen abominable" (Congregación para la Doctrina de la Fe 1987: I, 1). Se sabe que el abandono de los niños que nacen fue -y es aún- tolerado en algunas culturas (véase Feen en Bondeson y otros 1983: 283-289). M. Tooley (1972 y 1983) se erigió en el ardiente defensor del derecho de las personas a elegir positivamente el aborto o el infanticidio (8). Del mismo modo, algunos autores consideran como una falta moral grave traer al mundo a sabiendas un niño con taras (véase Shaw en Bondeson 1983: 273-279): eso sería una falta de respeto hacia esa persona futura que obligamos a vivir disminuida y hacia la comunidad moral. Sin embargo, y por las mismas razones, ningún Estado, ningún miembro de la comunidad moral, podría constreñir a una persona a un acto de eugenesia.

2) La experimentación sobre un embrión humano, in vivo e in vitro, con las mismas precauciones que cuando se experimenta sobre un animal, es perfectamente aceptable; pero requiere el consentimiento de los progenitores y atención a sus posibles consecuencias, pues, si la acción supone que viva a un ser que se convertirá en persona humana, se es responsable ante esa persona. Esto implica una actitud científica opuesta al empirismo de la posición "biológica". Aquí no se intentará terapia extraordinaria alguna para "salvar" un feto particular sin antes haber evaluado científicamente esa terapia sobre embriones experimentales que no dejaremos que se desarrollen. 
Juzgamos, en efecto, que no es lícito intervenir sobre un feto "por su bien" sin estar razonablemente seguros de que la persona futura podrá ratificar la elección que se le impone. Esto significa que es moralmente preferible matar a un feto que dejarlo vivir dañado (pensamos en lesiones producidas por rubéola, por talidomida) y que no hay por ello obstáculo ético a que un embrión o un tejido embrionario sean utilizados como medios con vistas a un fin humano.

3) Toda transacción comercial que concierna a seres humanos prepersonales (por ejemplo, madres portadoras) es admisible, siempre que ninguna persona sea forzada a hacer lo que no quiera. Kant decía -lo hemos recordado- que el respeto se debe a las personas, no a las cosas, y colocaba sin ambigüedad a los animales del lado de las cosas. "Las cosas pueden suscitar en nosotros la inclinación e incluso el amor, si son animales, o también el temor (...), pero nunca se les debe respeto" (Kant 1788). Podemos amar a un feto humano, no le debemos respeto. Los defensores del criterio "ético" de la persona ponen de relieve que las Iglesias cristianas nunca han exigido el bautismo o la ceremonia de enterramiento para los productos de abortos naturales (que en los hospitales, incluidos los hospitales católicos, son habitualmente incinerados con el resto de desechos humanos). Agregan que de todos modos sería imposible tratar con consideración el "despojo" de óvulos fecundados (numerosos: uno de cada dos o tres) que abortan en las dos primeras semanas y son eliminados con las menstruaciones, incluso sin que la madre sepa que ha estado embarazada.

La posición neo-kantiana tiene el doble mérito de fundar una amplia tolerancia para las elecciones morales diferentes y de insistir sobre la responsabilidad que tenemos, no hacia un feto, sino para con las personas que nos sucederán. La idea de que nuestros niños puedan tener derecho a pedirnos cuentas si nos ponemos a fabricar clones humanos o a desequilibrar la sex ratio es relativamente disuasoria: la experiencia americana ha mostrado ya que la posibilidad de sanciones obtenidas por niños contra padres o médicos que se condujeron de modo irresponsable no es solo teórica. Con esta reserva, está claro que en el plano legislativo o reglamentario se tiende aquí hacia una actitud permisiva. La ley no podrá ni imponer una práctica eugenésica, ni prohibir a las mujeres embarazadas el recurso al aborto, ni impedir a las parejas estériles recurrir a la FIVYTE; tampoco podrá, por otra parte, obligar a los ciudadanos hostiles a esos procedimientos a pagar para que sean ofertados a los demás como un servicio gratuito. La ley tampoco podrá prohibir a los investigadores que investiguen; a lo sumo puede prever una concertación previa a las inversiones en investigación (quienes entregan fondos para la investigación tienen derecho a que se cuente con su acuerdo con respecto a lo que los investigadores hacen con su dinero); la ley es sobre todo guardiana de los derechos de las personas (un médico que ejerciese presión sobre sus pacientes para que donen óvulos a la ciencia, o que tomara óvulos durante las intervenciones quirúrgicas, ignorándolo sus pacientes, penable con sanciones, incluso si el trabajo científico realizado gracias a esos óvulos es de gran valor).

El Consejo de Europa (1986) se mostró partidario de que fuesen vedados por la ley en todos los países los temas de investigación juzgados "desviados" (partenogénesis humana, fertilización cruzada hombrechimpancé, posibilidad de desarrollo de un embrión humano en un útero animal, etc.). Esta prohibición sería inaceptable (y ridícula) para un neo-kantiano, que no ve nada de inmoral en transgredir las barreras "naturales" y que, por contra, no puede admitir que a un equipo de investigadores responsables se le impida emprender una investigación, incluso aunque no pueda argumentar públicamente el interés científico y la aceptabilidad ética del proyecto.

En suma, la posición "ética" reivindica para las personas la libertad de asumir sus elecciones. Pero las expone a temibles problemas de casuística en las fronteras: ¿por dónde pasa el justo límite entre persona y no-persona? ¿Cuándo se convierte el niño pequeño en persona? ¿Quién es verdaderamente autónomo?, ¿cuándo? Y ¿quién tiene el derecho a decidir que alguien es, o no es, verdaderamente autónomo? ¿Cuándo es necesario ejercer respecto a un menor un paternalismo ilustrado?, ¿cuándo es necesario tratarlo como un sujeto libre y responsable? Hay quienes insinúan que no hay criterios "intrínsecos" claros y que se llega a ser persona porque se es reconocido como persona por otros seres humanos que se reconocen ellos mismos como personas (Solomon y Pucetti en Bondeson y otros 1983: 209-226 y 174-179). Engelhardt afronta la dificultad (1986: caps. 4 y 6), mantiene los criterios intrínsecos, discute varios casos dudosos (atraso mental profundo, comas prolongados) y concluye que es prudente 
que el concepto social de persona sea más amplio que el concepto ético (por ejemplo, el niño tiene derechos desde su nacimiento, antes de poseer alguna autonomía personal).

Concluyendo de una manera poco rigurosa, estamos seguros de no excluir de la comunidad de los agentes morales a ningún ser humano que fuese susceptible de formar parte de esa comunidad (9). Pero estas fronteras, que se presuponen amplias, han sido contestadas en nombre de experiencias de "regresión" durante las cuales algunas personas habrían revivido momentos de su vida intrauterina y su "decisión" de nacer (Wood y Westmore 1985). Kant mismo no fue absolutamente insensible a la idea de que la autonomía biológica, con su normatividad espontánea, prefigura la autonomía moral.

\section{El pragmatismo de los "comités de sabios"}

Respecto a la cuestión que nos ocupa, las dos posiciones extremas descritas más arriba (10) están en completo desacuerdo, salvo en un punto. Confunden en la misma reprobación, o aprobación, prácticas que la conciencia moral común no juzga moralmente equivalentes: el infanticidio y llevar dispositivo intrauterino, la selección genética de embriones antes de inducir un embarazo y el aborto selectivo durante el embarazo, etc. De aquí esta intuición: cada una de las dos actitudes es respetable como elección individual, ninguna es practicable como elección de la sociedad, una porque arroja la desconfianza y la prohibición sobre hábitos ampliamente admitidos (y rechaza el dominio humano de la procreación, que se ha convertido en un hecho), la otra porque comporta el peligro de que los débiles, los retrasados mentales, los dejados-de-cuenta-del-desarrollo, sean excluidos de la comunidad ética (y pone una confianza probablemente excesiva en la razón humana individual). Pero ¿cómo fundar filosóficamente una posición intermedia, un "justo medio" entre denegar al embrión humano todo estatuto personal y conferir a una célula la misma dignidad moral que a un ser consciente y racional?

La experiencia de diversas comisiones nacionales que han reflexionado sobre las nuevas técnicas de procreación y las perspectivas abiertas por la ingeniería genética parece mostrar que se ponen bastante fácilmente de acuerdo, en la práctica, sobre lo que es aceptable (por ejemplo, llegar a corregir en el embrión una enfermedad genética), lo que es inadmisible y debe eventualmente estar sancionado (por ejemplo, la creación de quimeras o de híbridos hombre-animal), lo que es prematuro pero podría ser explorado con prudencia (por ejemplo, la posibilidad de trasladar los embarazos humanos fuera del útero humano).

Lady M. Warnock, que dirigió los trabajos del Comité británico, sostuvo en un artículo (1987) un punto de vista resueltamente pragmático. Nuestras posiciones filosóficas son inconciliables: dejémoslas de lado. Los criterios intrínsecos de la personalidad son incoherentes, los criterios relacionales son injustos: cesemos de preguntarnos cuándo el embrión llega a ser "persona", busquemos qué derechos debería tener y qué modificaciones es necesario aportar a la ley para que los adquiera. R. M. Hare (1987) aprueba esta resolución: no perdamos nuestro tiempo -dice- en discusiones ociosas sobre la naturaleza del ser embrionario. Lo que debe ser no se deriva de lo que es. La verdadera cuestión es saber cómo el embrión debe ser tratado. El Comité británico, por ejemplo, recomendó que la utilización de embriones humanos con fines de investigación científica fuese ilícita en un plazo de 14 días tras la fecundación. Este límite es arbitrario. M. Warnock cree que, a pesar de esta arbitrariedad, es importante sentir que se pueden poner límites sin caer ni en la ineficacia de toda prohibición ni en la angustia de ser arrastrado por el torrente del progreso científico-tecnológico (11).

No obstante, Warnock piensa que el límite fijado no es enteramente arbitrario. Es necesario tener en cuenta -dice ella- lo que es el embrión precoz: un paquete de células. El decimocuarto día corresponde poco más o menos a la aparición de la "línea primitiva" sobre el disco embrionario, es el último momento en el que los gemelos pueden formarse. El argumento es tomado de R. Edwards (uno de los "padres" de los primeros bebés-probetas británicos). Un paquete de células que no tiene individualidad propia (puesto que puede dar por división gemelar varios individuos) y que no sufre (puesto que no tiene el más pequeño comienzo de esbozo de sistema nervioso) puede y debe ser tratado de distinto modo a como se 
trata un feto de seis meses que tiene forma humana, un sistema nervioso diferenciado y un cerebro en vías de maduración. Este argumento está ligado a una filosofía utilitarista: la posibilidad de hacer sufrir impone un límite a nuestras intervenciones. M. Warnock lo completa con otro: debemos abstenernos también de investigaciones que, sin causar sufrimiento al objeto estudiado, ofendan moralmente a una mayoría de nuestros contemporáneos en su sensibilidad. Conclusión: podemos investigar sobre el embrión humano hasta los 14 días, porque estamos seguros, por una parte, de que no sufre, y por otra, de que nuestros contemporáneos se conmueven menos por un paquete de células humanas que por animales utilizados en los laboratorios de investigación biomédica.

M. Warnock quiere mostrar que se pueden poner barreras morales como esa sin suponer que el embrión humano llega a ser "persona" a los 14 días. Pero no prueba que la deontología buscada sea independiente de toda ontología; al contrario, puesto que la norma anterior está explícitamente fundada sobre lo que es el embrión precoz. Creemos que lo que se busca bajo el amparo del pragmatismo es una ética fundada en una ontología progresiva, de acuerdo con la intuición, muy simple y común, de que el ser embrionario es un ser en desarrollo, y que, en el caso de una célula viviente que puede llegar a ser un feto de cinco meses y este un niño de cinco años, nuestras obligaciones morales no pueden ser las mismas con respecto a esos tres seres vivientes.

Los utilitaristas australianos expresan esta evidencia de un modo un tanto provocador, pero que no deja de recordar el enfoque aristotélico de la cuestión (Kuhse y Singer 1985). Al comienzo de su desarrollo dicen- el embrión humano no tiene más psiquismo que un vegetal ("que una lechuga"); no hay, pues, obstáculo moral para, por ejemplo, poner células embrionarias en cultivo; por otra parte, es mejor que los laboratorios farmacéuticos puedan comprobar en células embrionarias humanas, mejor que en animales adultos (como lo hacían), la teratogenicidad de los medicamentos. Cuando aparece en el embrión una sensibilidad animal, le debemos las mismas consideraciones que a todo ser movido por una sensibilidad animal y, en particular, tiene "derecho" a que no se le haga sufrir. El respeto en el sentido kantiano no puede ser otorgado antes de que ese ser comience a perseguir fines racionales.

Las comisiones de ética oficiales se expresan con menos severidad. El comité consultivo de ética del ministerio americano de la Salud (DHEW), cuando se pronunció sobre los protocolos de investigación ligados a la fecundación in vitro, afirmó que se le debe al embrión humano un profundo respeto, pero no un respeto tan pleno como el que está implicado en los "derechos del hombre": "The human embryo is entitled to profound respect; but this respect does not necessarily encompas the full legal and moral rights attributed to persons" (Ethics Advisory Board 1979). Cuando se repite que el embrión humano, incluso congelado, no es "ni un material ni un producto de consumo" (Colegio de Médicos, Francia, declaración del 21 de octubre de 1986), se quiere recordar que es más que una "cosa" (contrariamente a lo que implica la tesis neo-kantiana). $Y$ si no se pensase (contrariamente a lo que implica la tesis biológica) que el feto crece en dimensión personal a medida que se acerca al nacimiento, no nos tomaríamos tanta molestia por mejorar los resultados del diagnóstico prenatal y hacer abortar lo antes posible, durante el embarazo, a los seres malformados que sería más fácil suprimir tras el nacimiento. Quedan por explicitar las intuiciones filosóficas subyacentes a estas conductas de prudencia, a esa sabiduría práctica. Se concentran en la noción de persona humana potencial.

Que el embrión humano es una "persona humana potencial" es lo que dijeron el Comité Consultivo Nacional de Ética (CCNE) en Francia (en 1984), el Comité permanente de los médicos de la Comunidad europea (en 1995) y otros comités. Así, el CCNE, en su "Recomendación sobre las muestras de tejidos de embriones o de fetos humanos muertos con fines terapéuticos, de diagnóstico y científicos", escribe: "El embrión o el feto debe ser reconocido como una persona potencial que es o ha sido viviente y, por ello, el respeto se impone a todos". El informe Warnock (1984: § 11.22) emplea la expresión "ser humano potencial" (potential human being), el informe Benda escribe: "Entwicklungsform eines menschlichen Subjekts" (Grupo de Trabajo del Ministerio Federal 1985: § 1.3).

Es interesante observar que la noción de persona humana potencial es recusada por los defensores de los dos bandos extremos presentados en los apartados anteriores. En el bando personalista, se denuncia la "mistificación" que supone hacer creer que lo que aún no es, está ya presente (Tooley 1983). 
Engelhardt (1986: cap. 4) dice que el término "potencial" implica que la persona se encuentra ya ahí en potencia, en un embrión que no tiene aún sistema nervioso ni por consiguiente, a fortiori, conciencia ni razón, lo cual es absurdo; prefiere decir que el embrión es una "persona posible". En el bando vitalista se sostiene que el embrión es una "persona actual" (Moraczewski, en Bondeson y otros 1983: 308-309). Tettamanzi (1986) arguye que la humanidad no es "potencial" en el embrión, sino plena y entera; es cierto, dice él, que el ser humano posee, en todos los estadios de su vida, un "potencial de desarrollo", pero incluso incompletamente desarrollado es enteramente humano. Hasta en el bando de los utilitaristas y empiristas se reconoce no estar muy a gusto con este concepto de potencialidad, del que temen sus usos abusivos. Para M. Warnock (1987) la potencialidad de ser humano no funda un derecho a llegar a ser tal, pues no implica el deber de hacer vivir; los derechos del embrión en un momento dado están en relación con su ser actual, no con lo que el embrión es en potencia. Tooley (1983) y Kuhse y Singer (1986) fustigan el argumento de que no se debe destruir ese embrión humano porque quizá puede ser un Mozart "en potencia". Este argumento, dicen ellos, nada prueba, o prueba demasiado. No prueba nada, porque del hecho de que el embrión de gallina sea un pollo potencial no resulta que no tengamos derecho a hacerle lo que no tenemos derecho a hacerle a un pollo. Prueba demasiado, porque condena, por denegar quizás la existencia a un genio potencial, a toda persona que evita tener un niño cuando pudiera tenerlo.

Valerosamente, el CCNE (1986: § 13 y 14) intentó "fundar en razón" su recurso a la noción de persona humana potencial. Admitió que las propiedades del ser personal aparecen de manera "progresiva" y que "desde la concepción ese desarrollo hacia el ser personal ha comenzado". Insistió en la necesidad de enraizar esta personalidad en formación tanto en una realidad biológica (el embrión es humano en virtud de un genoma y de una sucesión de niveles de organización, descrita por los histólogos y embriologistas) como en una realidad "antropológica y cultural" (el embrión se humaniza en virtud de un "proyecto parenteral", de una "narración familiar", de un reconocimiento jurídico). Como antes, ontología sustancial y ontología relacional se llaman la una a la otra, pero lo hacen evolucionando la una con la otra. Su política de "prudencia" conduce al CCNE, que mantiene el dualismo cosas/personas (y coloca, sin dificultad aparente, a los animales del lado de las cosas), a situar antes al embrión humano del lado de la persona. "El embrión humano desde la fecundación pertenece al orden del ser y no del haber, de la persona y no de la cosa o del animal. Desde el punto de vista ético debería ser considerado como un sujeto en potencia, como una alteridad de la que no se podría disponer sin límite y cuya dignidad asigna límites al poder o al dominio de los otros" (1986: § 14).

Como hemos visto, la idea de que desde las primeras células embrionarias el embrión humano tiene una dignidad superior a la de un animal adulto es extraña a los filósofos utilitaristas. Estos poseen sentido de la unidad de lo viviente y dan a los niveles de desarrollo una importancia más crucial que a un genoma específico; y para ellos, en una palabra, en el estadio en que tiene la sensibilidad de una ostra, el embrión humano tiene la dignidad de una ostra. La posición del CCNE, que otorga al hombre un lugar especial dentro de la naturaleza, posee otras razones filosóficas (heterogéneas, sin duda en parte tomistas). "Lo que está en potencia en el embrión humano, hasta el punto donde han llegado hoy los conocimientos y los poderes biomédicos, no pueden separarse el destino de un ser singular y una parte del porvenir de la misma humanidad" (1986: § 18). Debemos respetar a la vez en el embrión humano una "singularidad individual" y una idea de la especie. "Al elegirme yo, elijo al hombre", decía Sartre. El CCNE defendió (en 1984) que el pre-embrión (el cigoto humano antes de su nidación, en los estadios donde se le congela) merecía respeto "en tanto que elemento del patrimonio humano", lo que se entiende a la vez en el plano objetivo (accedemos a la libertad de modificar el genoma de muestra especie, no haciéndolo para no importa qué) y en el plano simbólico ("nuestra relación con el embrión es significativa de la moralidad y de nuestra relación [...] con el género humano mismo").

El respeto de la singularidad individual se comprende bajo dos aspectos. Bajo un primer aspecto, la singularidad individual condiciona la libertad futura y se vincula con la regla neo-kantiana: cuando se interviene sobre un embrión con la intención de que viva, uno debe ponerse en el punto de vista de "la persona real que podría llegar a ser" y "no comportarse nunca en relación al embrión de una manera a la que esa persona no podría libremente adherirse por sí misma (CCNE). Bajo un segundo aspecto, la singularidad individual es la organización embrionaria misma en su estado actual de desarrollo y se 
relaciona con las filosofías de la autonomía biológica (Canguilhem 1950, Ruyer 1946) que se inclinan ante esta normatividad orgánica espontánea (de la que la libertad personal no sería más que su prolongación); se relaciona, también, con una vieja tradición médica de complicidad con esta normatividad (12), complicidad que no es un respeto de la vida, sino un respeto de normas inherentes a lo viviente: "la ética no ordena tener por sagrado al orden natural" (CCNE 1986: § 16).

En cuanto a la unión en el ser humano de una generalidad (tipo de la especie) y de una singularidad, puede comprenderse por la (difícil) doctrina tomista de la individualización por la materia, que daría un fundamento filosófico a las recomendaciones del CCNE referentes a la investigación sobre el embrión in vitro. Establecer que esta investigación debe confrontar la "doble exigencia" del respeto de la "potencialidad de la persona" en el embrión y del respeto de la "dignidad de la ciencia" (CCNE 1986: § 1), es en efecto suponer que el compuesto solo llega a ser plenamente respetable en su singularidad después que la forma humana se haya actualizado suficientemente para permitirle llegar a ser coautora de sí misma. Ante esto, es el tipo humano en vías de actualización lo que es respetable y, en la medida en que mediante nuestra actividad científica intervenimos en esa actualización, debemos también respeto a nuestro propio poder de intervención.

Para pensar el estatuto del embrión en la perspectiva de los nuevos poderes que nos corresponden, "las referencias culturales faltan en parte" (CCNE 1986: § 1). Pero no faltan totalmente. En primer lugar, en todas las culturas tradicionales existen ritos que giran alrededor del embarazo, el nacimiento, la imposición del nombre, los cuales subrayan la accesión progresiva del pequeño hombre al pleno estatuto de persona (véase Perkoff, en Bondeson y otros 1983: 159-166, y Actas del Coloquio 1985), y en nuestra propia tradición occidental ha habido, además, discusiones filosóficas y teológicas sutiles sobre la naturaleza del feto (13). Después, nuestro derecho ha conservado rasgos de esas preocupaciones. Es cierto que los "derechos de la personalidad" (de acuerdo con la vieja doctrina que asocia la animación con la respiración) se aplican desde el nacimiento del viviente (primer grito) hasta la muerte (último suspiro); pero la ley otorga al ser prepersonal una protección creciente, desde su concepción a su nacimiento. Antes de la nidación, el embrión no está protegido del todo (es el "vacío jurídico", juzgado preocupante en relación a los embriones in vitro); después, se protege poco en la medida en que la ley autoriza la interrupción del embarazo en algunas condiciones; por último, a partir del tercer mes aproximadamente, está muy protegido, a medida que la interrupción del embarazo está sometida a condiciones estrictas (motivo médico) y las mujeres embarazadas se benefician de una protección. El jurista suizo O. Guillod (1986) muestra cómo los desarrollos recientes conducen al derecho a acentuar esta tendencia, al definir una zona intermedia entre las cosas y las personas: "Los juristas deben apartarse de la dicotomía cosas/personas". Se trataría de profundizar la noción de "bien de la personalidad". ¿Soy propietario de mis células, de mis gametos? Los juristas no son unánimes. Algunos piensan que la propiedad es absoluta, de modo que uno podría vender su sangre y sus órganos; otros consideran esos bienes como posesiones que pueden donarse, pero con las que no se puede comercial; por último, otros insisten en que no tenemos propiedad de dichos bienes, sino simple disposición, y que el "don de gametos" no es una donación.

En la última hipótesis nuestros gametos, sin ser personas, no son en verdad asimilables a las cosas. Toman parte de nuestra "esfera personal". Guillod (1986) explica que los "derechos de la personalidad" son negativos o defensivos; protegen la esfera personal. Puedo oponerme a la utilización de mis células (prohibir que otra pareja se sirva de mis óvulos), no puedo imponerlo (exigir que otra mujer se beneficie de mis óvulos supernumerarios). ¿A quién pertenece el embrión precoz? A sus progenitores. Según Guillod, el embrión, en principio englobado en la esfera personal de sus padres (que disponen de él libremente: "píldora del día después", por ejemplo), se libera de ellos poco a poco para constituir su esfera propia a medida que el derecho lo protege más (y le reserva la disposición de sí mismo). Esa protección es negativa (y no funda para un embrión "derecho" alguno de exigir un útero para desarrollarse). La cuestión difícil es saber en qué sentido el embrión precoz "pertenece" a sus genitores. La noción de "propiedad" es casi unánimemente rechazada (por ejemplo, Ontario Law 1985, Annas y Elias 1983: § 7). El informe Warnock habla de un "derecho de uso" (1984: § 10).

La tendencia de los comités de ética ha sido considerar que el consentimiento de los genitores es 
necesario, pero no suficiente, para las manipulaciones de embriones in vitro (los protocolos experimentales deben estar controlados por comisiones científicas y éticas), lo que da a esos embriones, si no más derechos que a otros, al menos una mayor protección, al instituir una especie de tutela de la colectividad. ¿Se puede ir más lejos y, como sugiere por ejemplo G. Annas (1983), dar a los embriones en las negociaciones que les conciernan representantes que hablen en su nombre, como si tuviesen una esfera personal propia? Esto iría contra una muy fuerte tradición de respeto de la intimidad familiar. C. Whitbeck añade (en Bondeson y otros 1983: 249-258) que, si se tuviesen mejores informes de la experiencia de la maternidad (que posee también un marcado componente cultural), se vería cómo la relación del adulto con un feto o con un niño pequeño no es contractual; es absurdo aplicar una ética contractual de los derechos y deberes (yo respeto tu derecho, tu respetas el mío). Para llevar un feto, luego un recién nacido, hasta ser, dice ella, "una persona que habla", es necesario mucho más que la no interferencia y el respeto de los derechos; es necesario satisfacerle sus necesidades, cuidar de su persona; y esa parte carnal que se espera de las madres, si es indispensable, no podría ser exigible. Donar sangre o médula no es exigible. Si la colectividad decidiese que los embriones tienen derecho a todo lo que es indispensable para llegar a ser plenamente personas, debería hacer por ellos lo que la Iglesia hizo antiguamente por los niños abandonados al nacer: recogerlos, criarlos (¿incubadoras?), organizar su "adopción" -especie de experimentación psicosocial arriesgada que no está claro que sea preferible a la situación actual en la que los embriones, incluidos en la esfera personal de sus genitores, pueden ser donados por estos a la ciencia.

Quizás lo que nos falta para concebir el estatuto del embrión humano es un pensamiento filosófico y antropológico documentado por el trabajo científico. Las referencias culturales que impregnan nuestro derecho y nuestras mentalidades están vinculadas, en efecto, a una embriología tosca, poco diferente de la embriología aristotélica, mientras que nuestra filosofía moral ha estado más atenta a los condicionamientos socio-económicos de la libertad que a sus condicionamientos orgánicos. Los extraordinarios avances realizados en biología de la procreación están aún mal asimilados. No hay más que ver cómo algunos tomistas se han alineado altivamente con la tesis de la animación inmediata al amparo de los descubrimientos de la genética (véase Regnier 1974: 490-493), como si la genética hubiese probado que estando todo preformado en los cromosomas lo adquirido no tuviese función alguna. Sorprende, también, oír hablar de la concepción como "el principio de la vida", cuando la concepción supone una continuidad de la vida (los gametos están vivos, no hay generación espontánea, ninguna vida que no sea trasmitida: véanse las elocuentes páginas de Ruyer 1946).

Si se acepta la idea de una continuidad de la vida y de una accesión progresiva de cada generación humana a la vida personal, una de las vías más fecundas es la de la reflexión sobre los "umbrales" de desarrollo. Es difícil pensar el cambio, más difícil aún es pensar el desarrollo continuo de un ser que permanece él mismo al llegar a ser otro. La desvalorización de la ontología sustancial torna difícil el acceso a los conceptos filosóficos pertinentes (potencialidad, actualización...).

Pero la ciencia describe etapas en el desarrollo embrionario y es natural interrogarse con los científicos sobre lo que esas etapas pueden significar para la accesión hacia el ser personal. Muchos autores próximos a la posición "biológica" admiten, por ejemplo, que no es razonable atribuir "personalidad" a un montón de células que puede aún llegar a ser dos organismos distintos; si es exacto que la determinación individual se adquiere en el transcurso de la tercera semana con la aparición de la línea primitiva ("organizador primario") y la pérdida de la "plenipotencia" celular, de ello se sigue que el embrión no cumple una de las condiciones mínimas de la personalidad.

Esto relativiza la importancia que se ha intentado acordar al momento de la fecundación (véase, por ejemplo, Smith 1983 en una perspectiva tomista; McCartney, en Bondeson y otros 1983, muestra como muchos de los teólogos ortodoxos, inclusive el papa Juan Pablo II, han sido sensibles a este argumento). Pero el presupuesto filosófico de que no puede haber ahí vida humana personal sin individualidad orgánica subyacente merece un examen atento, porque la individualidad del cigoto, del óvulo, del espermatozoide, no ofrece tampoco duda: ¿en qué es menos un individuo personal el cigoto que el embrión de tres semanas? 
Otro umbral significativo es la aparición en el ser embrionario de una capacidad sensitiva (lo que supone que se establece una distinción entre la sensibilidad de una célula y la sensibilidad de un organismo pluricelular poseedor de un sistema nervioso). Para la mayoría de los filósofos utilitaristas, la existencia de una capacidad de sentir funda un derecho a no sufrir, pero no forzosamente un derecho a vivir. L. Fleming (1987) contesta este punto de vista. Establece (con los utilitaristas) que el Bien para un ser vivo consiste en la satisfacción de sus aspiraciones, el Mal (sufrimiento) reside en la frustración de sus deseos o aspiraciones y todo deseo es correlativo a un derecho (a no ser indebidamente frustrado). Conviene, también, en que el feto, antes de ser capaz de experimentar la frustración, no tiene derechos. Pero piensa que, a partir del momento en que el feto comienza a ser capaz de desear, los derechos que eso le confiere implican un derecho a continuar existiendo para obtener satisfacción; lo mismo si los deseos son esporádicos y no están unificados en la unidad de un sujeto que desea.

Otros autores estiman que no se puede comenzar a evocar derechos personales antes de que los deseos sean los de un sujeto que tenga un mínimo de conciencia, y esta conciencia no puede existir antes de que se desarrollen los centros cerebrales competentes. La cuestión de la conciencia está ligada a la cuestión de la capacidad de comunicación. Todo el mundo admite que la adquisición del lenguaje es una etapa decisiva en la formación de la persona (por ejemplo, Malherbe 1985), pero la puesta en evidencia de una capacidad de comunicación no verbal (reconocimiento de la voz, por ejemplo) justifica quizás que se pongan en juego los criterios relacionales de la accesión al mundo de las personas antes incluso del nacimiento y en el transcurso de los primeros meses (Stern 1985).

La viabilidad parece constituir aún una etapa importante para el estatuto ético del feto, puesto que un prematuro que viene al mundo y es viable es socialmente una persona. La importancia de esto ha sido puesta en duda. En efecto, el umbral de viabilidad se ha rebajado con los progresos técnicos de los últimos decenios y no es imposible que se rebaje aún más, hasta que los esfuerzos de los pediatras para hacer sobrevivir en buenas condiciones (es decir, sin defecto neurológico) a los prematuros cada vez más jóvenes alcancen un día los esfuerzos de los biólogos para criar a los embriones precoces en medios de cultivo apropiados. No obstante, Engelhart ha abogado vivamente (en Bondeson y otros 1983: 183-208) por que se le conserve al umbral "natural" de viabilidad su significación moral de límite más allá del cual la madre pierde el derecho a disponer del feto como puede dispone de su propio cuerpo, porque el feto ha llegado a ser un organismo capaz de vida independiente.

En verdad, este punto de vista puede discutirse. Lo que queremos sugerir es que las confrontaciones transdisciplinares que han resultado del trabajo de las comisiones de ética que reflexionan sobre las tecnologías de la procreación pueden reanudar -más allá de las recomendaciones inspiradas por el pragmatismo- un vínculo entre ontología y ética. Los textos ya publicados sobre el estatuto del embrión (feto) humano muestran con suficiencia nuestra capacidad para fundar elecciones en un pensamiento filosófico, ya sea de inspiración empirista-utilitarista, como pasa con frecuencia en los países de lengua inglesa, o ya anuncie una posible renovación del hilemorfismo aristotélico, en el viejo continente.

\section{Notas}

El presente texto fue publicado en el núm. 151 (junio de 1989) de la revista Esprit, pp. 86-120. Una primera versión del mismo apareció en la Revue de métaphysique et de morale, número especial sobre "Bioética", 1987 (3). Traducción y adaptación de José Luis Solana Ruiz.

1. El desarrollo humano prenatal dura por término medio $270+/-10$ días ( 9 meses legales, 10 meses lunares, 40 semanas o 7 cuarentenas), como se sabe desde hace mucho tiempo (véase Aristóteles, Historia de los animales, VII, 548 ${ }^{a}$ 34-b14). Utilizamos el vocabulario consagrado por el uso. La fase embrionaria (ocho primeras semanas) es precedida por la fase fetal (de la novena semana hasta el término). Algunos llaman "pre-embrión" al embrión precoz (primera semana o dos primeras semanas). La madre comienza a percibir los movimientos del feto entre la semana decimosexta y la vigésima (lo que se 
llama en inglés quickening). Aristóteles fijó el umbral de viabilidad en 28 semanas. El umbral de viabilidad está situado actualmente en 24 semanas, para un feto que pese 600 gramos. Las ideas de la gente sobre el desarrollo embrionario son frecuentemente imprecisas. Wood y Westmore (1985) refieren que en 1984 el 40\% de los estudiantes interrogados al azar en la universidad Monash (Australia) ¡creían que el embrión de uno o dos días tiene cerebro! El embrión de un día es una célula que mide una o dos décimas de milímetro de diámetro, que se divide en dos células hacia el segundo día.

2. La definición clásica es la de Boecio: "Una persona es una sustancia individual de naturaleza racional" (Contra Eutychen el Nestorium, Sec. III). Pueden existir seres racionales no humanos. Tomás de Aquino trata de la persona en su capítulo sobre las personas divinas. Insiste en el hecho de que las sustancias racionales poseen "el dominio de sus actos": "no son simplemente intervenidas, como el resto, sino que actúan por sí mismas" (Summa Theologiae, 1, Quest. 29, Art, 1). La unidad de la persona es la de un acto de existir, de un "sujeto de existencia" (Summa Theologiae, III. Quest. 35, Art. 1). De alguna manera, la unidad de la persona humana es la de su alma intelectiva o racional; pero santo Tomás se cuida de precisar que la persona humana no se reduce a su "alma", no está hecha para subsistir separada del cuerpo (Summa Theologiae, I. Quest. 29. Art. 1. Sol. 5 el Quest. 90. Art. 4). Leibniz explica muy bien que por inmortalidad, en la tradición cristiana, se entiende que "no solo el alma subsiste, sino también la personalidad. Esto es, al decir que el alma del hombre es inmortal, se hace subsistir lo que hace que uno sea la misma persona, la cual conserva sus cualidades morales al conservar la conciencia o el sentimiento reflexivo interno de lo que ella es, lo que la hace capaz de castigo y de recompensa" (Ensayos de Teodicea, 1710, § 89). La doctrina de la metempsicosis no es una doctrina de la supervivencia personal en la medida en que, en cada migración de una vida a otra, las almas beben el agua del Leteo (pierden la memoria de su anterior vida: Platón, República, X). C. Renouvier (1903: cap. V, § LXII y LXIII) dice que la noción filosófica de persona es fruto de la alianza entre el monoteísmo judío y la filosofía griega: el Dios personal judeo-cristiano hace don de la personalidad del hombre aristotélico, individuo racional. La noción de persona se dilata en la filosofía de la llustración, al mismo tiempo que se desustancializa. Locke liga la unidad de la persona a la continuidad de la conciencia de sí reflexiva (Ensayo sobre el entendimiento humano, 1706, II, 27). Hume niega que haya unidad sustancial y desvincula la noción de persona de la de sustancia, en provecho del yo empírico o bien del yo trascendental. Para Kant, la persona es sujeto; su realidad noumenal se nos escapa. Kant se encuentra en la encrucijada de las tradiciones del personalismo realista (de Tomás de Aquino a los neoescolásticos, por ejemplo, Mounier) y del personalismo idealista (de Leibniz a Renouvier). Una filosofía personalista hace de las personas las realidades últimas. Para Tomás de Aquino, la persona es "lo que hay de más perfecto en toda la naturaleza" (Summa Theologiae, 1 Quest. 29, Art. 3); la persona humana es "un fin en sí", el término al que concurre todo el universo. Para Renouvier (1903, Intr.), la persona es la condición de posibilidad del mundo: "El conocimiento de la persona en tanto que conciencia y voluntad es el fundamento de todos los conocimientos humanos". Aparte de la línea personalista, la reflexión metafísica pos-kantiana aborda al sujeto como libertad (es decir, últimamente, en Sartre, como nada), mientras que el análisis fenomenológico lo aprehende como conciencia y retoma los problemas tradicionales: por una parte, el problema de la unidad del yo, "síntesis viviente" de un presente, un pasado y un futuro; por otra, el problema del sentido de los valores (normatividad). La idea de una fuente autónoma de actividad permanece central: "El cursus personae de un ser consciente y libre no es asimilable al cursus naturae: este último 'llega', el primero es 'producido' por el hombre y por eso sometido a evaluación ética" (Tettamanzi 1986).

3. J. Testart se pronunció vivamente por la libertad de evitar saber, a fin de no poder escoger con conocimiento de causa. "Reivindico una ética de la no-investigación" (Le Monde, 10-09-1986). En Francia, el Comité Nacional de Ética (1986, Recomendación, IIIa) recomendó una moratoria sobre las investigaciones dirigidas a posibilitar un diagnóstico genético en las células embrionarias obtenidas in vitro antes de transferir el embrión al útero, arguyendo que la disponibilidad del diagnóstico aumentaría la tentación de programar el nacimiento del niño en función de algunas cualidades juzgadas deseables. Un problema considerado como especialmente preocupante ha sido el de la selección del sexo, puesto que esta resulta posible. Corea del Sur conoció una oleada de abortos de fetos de sexo femenino cuando estuvieron disponibles los medios técnicos para diagnosticar el sexo dentro de los plazos legales de la interrupción voluntaria del embarazo, hasta el punto de que en 1986 las autoridades coreanas tuvieron 
que prohibir a los médicos que estos revelasen ese diagnóstico a los padres (Le Monde, 05-11-1986). Desde que se tomó conciencia (en el siglo XVII) de la estabilidad natural de la sex ratio, nos hemos preguntado siempre lo que pasaría si los padres tuviesen libertad para decidir el sexo de su progenitor. Los expertos responden que las consecuencias serían con probabilidad poco importantes si la elección fuese individual (es decir, al margen de una política colectiva para imponer una sex ratio concreta).

4. Los métodos contraconceptivos ("píldora") previenen la fecundación. Otros métodos (dispositivo intrauterino, "píldora del día después", RU 486) impiden la gestación, sea previniendo la implantación del feto fecundado, sea provocando un aborto muy precoz (contragestación). Creer que la persona humana comienza con la fecundación implica el rechazo de los métodos del segundo tipo. La Iglesia católica condena también la contraconcepción, dejando entender que no es legítimo impedir el acceso a la existencia a una persona posible, aun cuando no se pueda decir propiamente que tenga un "derecho a la existencia" (véase la nota siguiente).

5. "Nadie puede reivindicar, antes de existir, un derecho subjetivo a venir a la existencia; no obstante, es legítimo afirmar el derecho del niño a tener un origen plenamente humano gracias a una concepción conforme a la naturaleza personal del ser humano". La probeta y el útero artificial (incubadora) son "contrarios a la dignidad de ser humano que corresponde al embrión" (Congregación para la Doctrina de la Fe 1987: 1, § 6 y nota 32).

6. "Preservar la vida es más importante que vivir una 'buena' vida", decía Byron Sherwin, quien explicaba a propósito de la eutanasia que "según la ley judía, la vida debe ser preservada, incluso a gran precio" (cit. en Comisión de Reforma del Derecho de Canadá 1979: cap. 2). Pero ocurre que hay que elegir entre dos vidas: interrumpir un embarazo para salvar a la madre, por ejemplo. Varias reglas se proponen a veces para resolver ese dilema. Una regla talmúdica dice que la madre tiene preferencia sobre el niño hasta el momento en que, realizándose el parto, aparece la cabeza del niño; después de ese momento, la vida del niño tiene primacía. Es muy delicado elegir por otro entre la muerte y una vida "que no vale la pena". En 1980, en Gran Bretaña, un médico fue demandado por la asociación Life por haber dejado morir, ante la petición de los padres, a un recién nacido malformado. En 1982, en los Estados Unidos, un bebé (baby Doe) vino al mundo afectado de trisomía 21 y de una malformación digestiva, y necesitaba una corrección quirúrgica inmediata si se quería que sobreviviese. Los padres, en común acuerdo con el equipo médico, decidieron no operarlo. La administración del hospital llevó el caso a juicio y el juez confirmó el derecho de los padres a tomar esa decisión. El bebé murió al cabo de cinco días. Los medios próximos al movimiento por el "derecho a la vida" formaron un gran escándalo en la prensa; decían que la vida de un trisómico podía valer la pena de ser vivida y que se había dado más importancia al confort de los adultos que a la vida de un niño.

7. La ontología substancial y la ontología relacional están muy unidas, incluso cuando se trata de personas divinas, si hemos de creer a los teólogos cristianos. Se puede preferir uno de los aspectos, pero no se puede ignorar el otro. Hace poco, para justificar la libertad de abortar, y hoy para justificar la libertad de elegir entre los embriones que se van a transferir al útero y los que se van a dejar en el congelador, se ha intentado anclar la dignidad personal en una ontología solamente relacional. El colectivo cristiano que redactó en 1973 un texto favorable a una liberalización del aborto insistía en la insuficiencia de los criterios biológicos: "El empeño por definir una realidad objetiva del embrión, ¿no enmascara el miedo a tener que cargar con una verdadera responsabilidad?" (Colectivo Cristiano 1973). Introdujo una distinción entre "vida humana" y "vida humanizada"; la humanización se efectúa en la relación que se instaura entre el feto y sus padres que lo desean, lo reconocen, lo llaman a nacer. En ausencia de esa relación, el aborto sería un mal menor. Años después, el grupo de reflexión sobre bioética de Rennes subrayaba "la aporía de una definición substancialista y fija de la persona", y concluía que es necesario pensar la persona "como nudo relacional y no como sustancia objetivamente localizable", porque la persona "solo tiene su ser en su relación (...) con otras personas" (véase Lagrée 1986). Muy bien, la ontología relacional está de moda. Pero ¿quién no percibe que una ontología únicamente relacional, sin ningún anclaje sustancial, nos hace caer en lo arbitrario? Un ser humano puede ser deseado un día, rechazado el siguiente. ¿Es necesario aceptar que los ancianos a los que ya nadie quiere cesan de ser personas? 
8. El filósofo inglés R. M. Hare imagina el caso de padres que traen al mundo a un niño afectado, por ejemplo, de espina bífida (el caso no es excepcional en Inglaterra). Es necesario que elijan entre dedicar su vida a cuidar de ese ser impedido o bien tener otro niño tras haber dejado morir al primero. Hare (1987) dice que se puede justificar la elección de la segunda opción mediante el siguiente argumento racional. Entre dos vidas de las cuales una es ciertamente de mala calidad y la otra probablemente normal, hay que elegir la mejor; por consiguiente, es preferible dar su posibilidad "al niño que sigue en la lista de espera". Se trata de un argumento utilitarista (se deben "maximizar" las oportunidades de una vida de buena cualidad). El mismo argumento se esgrime con frecuencia para justificar el aborto de fetos anormales. Un personalista no aceptaría comparar la vida de una persona real y la de una persona "posible". Diría que toda la cuestión está en saber si ese recién nacido es realmente una persona. El límite "social" entre no-persona y persona se sitúa por lo común algunas horas después del nacimiento, lo que deja a los padres tiempo para poder tomar una decisión con la ayuda del equipo médico. Si el niño vive, él solo tendrá luego derecho a decidir, la ley lo protegerá de manera plena. Engelhardt piensa que la supresión de fetos o de recién nacidos incapacitados es totalmente compatible con la protección estricta de las personas con discapacidad, una vez que estas existan como personas.

9. H. T. Engelhardt piensa en realidad (junto con otros autores, por ejemplo: J. Fletcher, M. Tooley, P. Singer y $\mathrm{H}$. Kuhse) que la noción "social" de la persona se extiende demasiado y que debería ser admisible establecer que un enfermo en estado de coma vegetativo crónico o un recién nacido afectado de un déficit neurológico severo -en suma, que esos seres que en la jerga médica se les conoce como "vegetales"- no son personas y que, por tanto, no hay obligación de "prolongarlos" indefinidamente.

10. Existen representantes de las dos tendencias en todas las corrientes de pensamiento, como existen en todas partes personas que tienen aversión al riesgo y otras a quienes el riesgo las atrae. Una encuesta americana mostró que, contrariamente a lo que se podía creer, la proporción de gente favorable u hostil al aborto era casi la misma entre católicos y protestantes (Shannon, en Bondeson 1983: 7-8). El jurista australiano R. Scott señala con un toque de humor que en junio de 1985, con cuatro días de diferencia, el Times de Londres publicó una declaración del arzobispado (anglicano) de York afirmando que el pre-embrión no es una persona humana y una declaración del primado (católico) de Westminster aseverando que el pre-embrión es una persona humana. Añade que se encuentran disensiones análogas en las comunidades judía y musulmana. El informe sobre las procreaciones artificiales redactado en Francia a petición del primer ministro (véase Alnot y otros 1986) pone en evidencia una larga diversidad de opiniones.

11. A quienes objetan que el límite será transgredido, responde que hay buenas razones para creer lo contrario. Existen precedentes. La legislación británica que limita el uso de animales para la investigación es en general respetada por los laboratorios públicos y privados. Y en el caso de los embriones humanos, los mismos científicos han pedido que se les fijen reglas.

12. La medicina corrige a la naturaleza, pero contando para ello con normas inspiradas en equilibrios naturales. Esta vía media, entre el respeto ciego y el intervencionismo arbitrario, está bien descrita por $\mathrm{J}$. M. Thévoz (1985) desde una perspectiva protestante: "No se trata de seguir a la naturaleza de manera uniforme (...) tampoco es cuestión de ignorar totalmente su modo de acción". La deontología profesional puesta a punto por el diagnóstico prenatal traza la frontera entre las anomalías graves que hacen la interrupción terapéutica del embarazo (ITE) moralmente admisible y las anomalías benignas para la cuales la ITE debe ser rechazada: el médico "no podría (...) rehusar la interrupción del embarazo por una afección grave e incurable si esta es pedida por los padres, pero no puede admitirla cuando se trata de una malformación menor o curable quirúrgica o médicamente" (Maroteaux y otros 1984).

13. Es verdad que estas controversias están bastante olvidadas, incluso son rechazadas, como si se tuviese vergüenza a preguntarse cuándo el feto adquiere su alma racional. La pregunta "¿cuándo el embrión llega a ser una persona?" solo es, por tanto, la versión laica de la pregunta "¿cuándo la animación tiene lugar?". 


\section{Bibliografía}

Actas del Coloquio

1985 Génétique, procréation et droit. París, Actes Sud.

Alnot, M. O. (y otros)

1986 Les procréations artificielles. Rapprt préliminaire à Monsieur le Premier ministre. París, La Documentation Française.

Annas, G. (y S. Elias)

1983 "In vitro fertilization and embryo transfer: medico-legals aspects of a new technique to create a family", Family Law Quaterly, no 17 (2): 199-223.

Bondenson, W. B. (y otros)

1983 Abortion and the Status of the Fetus. Dordrecht, Reidel.

Canguilhem, G.

1950 Essai sur quelques problèmes concernant le normal et le pathologique. París, Belles Lettres.

Colectivo Cristiano

1973 “Pour une réforme de la législation française relative à l'avortement”, Études, n 338 (1): 55-84.

Comisión de Reforma del Derecho de Canadá

1979 Les crimes contre le foetus. Ottawa, Documento de trabajo nº 58.

Comité Consultivo Nacional de Ética (CCNE)

1986 Rapport éthique. París, La Documentation Française.

Congregación para la Doctrina de la Fe

1987 Instruction sur le respect de la vie humaine naissante et la dignité de la procréation. París, Éditions du Cerf.

Conseil d'État

1988 Sciences de la vie. De l'éthique au droit. París, Documentation française.

Engelhardt, H. T.

1986 The Foundations of Bioethics. Oxford University Press.

Fleming, L.

1987 "The moral status of the foetus: a reappraisal", Bioethics, $\mathrm{n}^{0} 1: 15-34$.

Fletcher, J.

1972 "Indicators of humanhood: a tentative profile of man", Hasting Center Report, n 2 (5).

Grupo de Trabajo del Ministerio Federal de la Investigación y de la Tecnología de la RFA 1985 Berichtdes Arbeitsgruppe In-vitro-Fertilisation, Genomanalyse und Gentherapie.

Guillod, O.

1986 "Implications juridiques de certains progrès scientifiques dans le domaine de la procréation et du génie génétique. Aspects du droit de la personnalité”, La semaine judiciarie, no 108 (8): 877-891.

Hare, R. M.

1987 "An ambiguity in Warnock", Bioethics, nº 1 (2): 175-178. 
Jouannet, $P$.

1986 "Reflexions à propos des problèmes éthiques soulevés par la congélation d'embryons humains", Médicine/Sciences, $n^{\circ}$ 2: 345-347.

Lagrée, J.

1986 "La personne humaine", Lettre d'information du CCNE, nº 6.

Malherbe, J. F.

1985 “L'embryon est-il une personne humaine?", Lumière \& vie, nº 34 (172): 19-31.

Maroteaux, P. (y otros)

1984 "A propos de l'Avis du CCNE sur le diagnostic prénatal et périnatal", Archives françaises de pédiatrie, no 11: 113-118.

Ontario Law Reform Commission

1985 Report on Human Artificial Reproduction and Related Matters. Toronto, Ministry of the Attorney General.

Kuhse, H. (y P. Singer)

1986 "Ethical issues un reproductive alternatives for genetic indications", en VII Congress of Human Genetics, Berlín, Springer-Verlag.

Regnier, M.

1974 "Le thomisme depuis 1970", en Belaval (ed.), Histoire de la philosophie, vol. III, París, NRF, Encyclopédie de la Pléiade: 483-500.

Renouvier, C.

1903 Le personnalisme. París, Alcan

Ruyer, R.

1946 Élèments de psycho-biologie. París, PUF.

Singer, P. (y H. Kuhse )

1988 Should the baby live? The Problem of Handicapped Infants. Oxford, Oxford University Press.

Smith, Philip A.

1983 "The beginning of personhood: a Thomistic perpective", Laval théologique et philosophique, $\mathrm{n}^{\circ} 39$ (2): 195-214.

Stern, D. N.

1985 The Interpersonal World of the Infant. A View from Psychoanalysis and Developmental Psychology. Nueva York, Basic Books.

Tettamanzi, D.

1986 "La recherche sur les embryons précoces, aspects éthiques", Osservatore Romano, 21 febrero 1986.

Théry, R.

1982 "La condition juridique de l'embryon et du foetus", Recueil Dalloz, n 33: 231-238.

Thévenot, $X$.

1985 "Le statut de l'embryon humain", Project, nº 195: 43-56.

Thévoz, J. M.

1985 "Un statut moral pour l'embryon? Recherche protestante", Le supplément, n 153: 113-124.

Tooley, M. 
1972 "Abortion and infanticide", Philosophy and Public Affairs, nº 2 (1): 37-65.

1983 Abortion and Infanticide. Oxford, Clarendon Press.

Warnock, M.

1984 Report of the Committee of Inquiry into Human Fertilisation and Embryology. Londres, Her Majesty's Stationery Office.

1987 “Do human cells have rights?”, Bioethics, n 1: 1-14.

Wood, C. (y A. Westmore)

1985 "Postcript: The significance of the early human embryo -a broad perspective", Clinics in Obstetrics and Gynaecology, 12 (4): 911-921. 